\title{
Diez tesis sobre el cambio político discontinuo en las políticas públicas medioambientales; Desde los costes de transacción y Ia complejidad de formulación en el caso de Ia Política Pesquera Común de Ia Unión Europea*
}

Ten theses on the discontinuous political change in environmental public policy from transaction costs and complexity of formulation in the case of the Common Fisheries Policy of the European Union

Miguel Gomis Balestreri**

Recibido: $18 / 01 / 2014$

Aprobado: 20/03/2014

Disponible en línea: 01/07/2014

\section{Resumen:}

Las políticas públicas son hoy día insuficientemente ambiciosas para revertir el daño medioambiental que genera el hombre. La mayoría de la literatura sobre el cambio en las políticas públicas analiza sus alicientes pero no sus limitantes. En este texto elaboramos una reflexión sobre el policy change desde la noción de los costes de transacción. Tras una revisión de los tres enfoques principales del desarrollo sostenible, de la modernización y democratización ecológicas, pasamos a enunciar diez tesis sobre

\section{Abstract:}

Nowadays public policies are insufficiently ambitious in order to reverse the environmental damage generated by man. Most of the literature that analyses policy changes tends to explain the incentives but do not give clear explanations about the limitation factors. We develop in this paper a reflection on policy change from the notion of transaction costs. Following a review of the three main approaches -sustainable development, ecological modernization and democratization- we expose ten theses on the

doi:10.11144/Javeriana.PAPO19-2.dtcp

* Artículo de reflexión.

** Politólogo, Doctorando en Gobierno y Administración pública del IUIOG/UCM con Master en Gobierno y Administración Pública del IUIOG/UIMP y Master en Finanzas y Estrategia de SciencesPo. Consultor en Gobernabilidad y Gestión Pública, Director General de CEPOA. Correo electrónico: miguel.gomis@gmail.com 
el papel de los costes de transacción en el policy change a partir del caso de la Política pesquera común de la Unión Europea.

\section{Palabras clave:}

policy change; cambio de políticas; política medioambiental; costes de transacción; complejidad; pesca; Unión Europea

\section{Cómo citar este artículo:}

Gomis, M. (2014). Diez tesis sobre el cambio político discontinuo en las políticas públicas medioambientales desde los costes de transacción y la complejidad de formulación en el caso de la Política Pesquera Común de la Unión Europea. Papel Político, 19(2). 601-630. http:// dx.doi.org/10.11144/Javeriana.PAPO19-2.dtcp role of transaction costs in the policy change from the case of the Common Fisheries Policy of the European Union.

\section{Keywords:}

policy change; environmental policy; transaction costs; complexity; fisheries; European Union 


\section{Introducción}

En un contexto en el cual los países ven acelerarse el número de desafíos vinculados a los acontecimientos climáticos extremos, la constatación de la degradación ecológica parece ser ya consensual en diversos ámbitos. A pesar de que el cambio climático haya sido el problema medioambiental más tratado por los medios (Boykoff y Roberts, 2008), hay sectores de actividad en los cuales la repercusión de la acción humana significa desde hace tiempo amenazas serias a la sostenibilidad. Podríamos situar en este registro la deforestación, la contaminación de acuíferos o la sobre-explotación de las reservas haliéuticas. Son muchos los temas medioambientales que no han recibido atención mediática. No por ello hemos de entender que no requieren cambios en las políticas públicas (PP) relacionadas. Se pueden citar por ejemplo el déficit de investigación sobre el llamado "efecto cóctel” (Sarigiannis y Hansen, 2012), las consecuencias de la contaminación marítima sobre consumidores de pescados, así como asuntos tan desconocidos y recientes como la preocupante gestión de las reservas mundiales de fosfatos (Scholz, Ulrich, Eilittä, y Roy, 2013).

La degradación del ambiente supone hoy día un desafío para los gobiernos, los cuales ya no solo tienen que legislar sino reconocer, en muchos casos, el fracaso de sus políticas. Verosímilmente este es el caso de la Política Pesquera Común (PPC) de la Unión Europea que revisaremos aquí. A pesar de la concienciación y la voluntad de muchos actores involucrados en la toma de decisiones tanto internacionales como nacionales, la incapacidad política para hacer frente a la degradación ecológica nos lleva a una pregunta sencilla empero de muy difícil respuesta: ¿̇cuáles son los frenos o incentivos al llamado policy change $(\mathrm{PCh})^{2}$ en temas medioambientales?

Esta misma interrogación es la que está en el corazón del debate teórico que propone modificar las reglas para la toma de decisiones. Dicha discusión ha generado tres enfoques principales (Dobson, 2007): el desarrollo sostenible (DS), la democratización (DE) y modernización ecológicas (ME). La primera propuesta está ligada al Reporte Brundtland y la incipiente toma de conciencia de la crisis ecológica. La segunda proposición deriva del ecologismo que según Arthur P. J. Mol (1999) nació en la década de 1980 de la mano de varios sociólogos, principalmente Martin Jänicke y Joseph Huber. Algo a notar es que como bien lo recuerda Blowers (1997), la modernización ecológica no mira el problema medioambiental como una amenaza sino más bien como una oportunidad frente a la cual se pueden dar ciertos procesos de redefinición tecnológica, productiva y valorativa. La tercera, derivada del ambientalismo, parte justamente del

\footnotetext{
${ }^{1}$ La interacción entre sustancias químicas cuyas consecuencias sobre la salud humana se desconocen. Este déficit se explica por la dominación hasta hace muy poco en todas las agencias reguladoras del enfoque de la dosis diaria admisible (IDA, más conocido como ADI por sus siglas en inglés) ${ }^{2}$ Se entiende por policy change el cambio no incremental en la formulación/diseño e implementación de las políticas públicas.
} 
aparente fracaso de la modernización ecológica (Warner 2010), proponiendo simple y llanamente la refundación de las instituciones democráticas (Bourg, 2010).

A partir de los presupuestos de estos tres enfoques analizaremos sus capacidades para engendrar el policy change desde los costes de transacción (CT). Podemos adelantar que a expensas de sus divergencias, en realidad los tres enfoques parten del mismo presupuesto - no forzosamente declarado-del insuficiente PCh. Es interesante ver que los defensores de cada modelo han respaldado la capacidad para generar policy change, infra-valorando las oportunidades generadas en el marco de los otros enfoques. La DE es sin duda la propuesta más radical y crítica, que al ser más reciente, conjetura el fracaso de los dos otros. Lo interesante reside también en el hecho de que el debate sobre los enfoques no ha buscado entender las raíces de la incapacidad de los sistemas políticos actuales. Y cuando lo ha hecho, no ha aportado explicaciones concluyentes. La existencia de esa escalada en la radicalidad de los enfoques deja entrever que la mayoría de los autores lo dan también por descontado; la urgencia ya no requiere buscar razones del fracaso sino claves para el éxito.

A despecho de parecer conservadores, el conocer los condicionantes del fracaso debería de considerarse como un paso fundamental para poder contemplar la necesidad de modificaciones en el régimen político democrático. Las alegres propuestas de parlamentarismos abiertos y participación no deberían tomarse como propuestas inocentes o utópicas. Empero cobrarían más lógica si se justificara la necesidad de superar los factores que limitan el PCh. Como es evidentemente en un campo de estudio muy amplio, nosotros nos limitaremos a enunciar diez tesis de explicación, las cuales fundamentamos en una lectura desde los costes de transacción. Esta noción económica ha sido empleada en ciencia política, aunque como veremos, con grandes desaciertos en razón de heurísticas que dejan de lado especificidades de la racionalidad política. Por todo ello desgranaremos las tesis sustentándolas en el caso de la política pesquera común de la Unión Europea (UE).

Las tesis enunciadas solo son una propuesta para la discusión. Bien es cierto que podrían orientar investigaciones posteriores destinadas a superar la simple especulación y aportar argumentos empíricos.

\section{Un estudio de caso: la Política Pesquera Común de la Unión Europea}

Como anunciado, para poder articular nuestras intuiciones sobre el papel de los costes de transacción en el PCh hemos elegido el caso de la PPC de la UE. Si bien las decisiones de este conjunto supra-nacional podrían ser consideradas como el fruto de un sistema de toma de decisión atípico, este sigue estando sometido a los condicionantes de rendición de cuentas y una diversidad de actores. Esta última va incluso más allá de la que suele estar involucrada en los contextos nacionales. Hemos escogido este ejemplo por cinco razones principales. 
Primero, tiene la ventaja de existir una muy amplia literatura sobre su desarrollo, especialmente sobre su último proceso de revisión que se llevó a cabo entre 2009 y 2013. Segundo, hay un cierto consenso sobre la existencia de un cambio substantivo en la formulación de la política en su versión del 2013. Tercero, estamos ante un tema medioambiental cuya evolución adelanta el camino que otras problemáticas pueden conocer y que actualmente aún no dan signos tan visibles como lo es la ya drástica disminución de las reservas haliéuticas (Hilborn, 2012). Cuarto, el acceso a profesionales del sector que han accedido a compartir sus impresiones con nosotros sobre la evolución de la normativa de la PPC. Quinto, antes del acuerdo sobre la reforma del 2014 no había claridad sobre el PCh y muchos se temían la frustración de una reforma ambiciosa. Tan es así, que Surís-Regueiro, Varela-Lafuente y Garza-Gil (2011, p. 599) sugerían: "In conformity with our observations, we estimate that the forthcoming reform of the CFP in 2012 will not imply, generally speaking, significant changes."

Por último buscamos precisar que la problemática sobre el PCh en el caso de la PPC es aún más sugestivo si consideramos la sorprendente decisión de la Eurocámara, la cual rechazó prohibir la pesca de arrastre en los grandes fondos marinos en un voto del 4 de noviembre de 2013, a semanas de que se aprobara la nueva PPC de 2013. Es decir, estaríamos ante un policy change que solo cubre algunos aspectos de la actividad pesquera y que excluye los temas más nuevos.

\section{¿Cuáles son las particularidades de las políticas pesqueras?}

Caddy y Seijo (2005) subrayan ciertas peculiaridades de la regulación del sector. La dificultad para la previsión sobre las reservas hace que se haya pasado de una toma de decisiones científica linear a una basada en el principio de precaución. Además, las nuevas tecnologías han supuesto un aumento de las capacidades de extracción, las cuales también han ido respondiendo a una modificación de los hábitos de consumo que han inducido un aumento de la demanda de productos del mar.

La modernización del sector ha sido compleja y desigual. Ante la problemática de la reconversión de la mano de obra, las políticas de los conjuntos regionales de cooperación pesquera no siempre han sido capaces de controlar la explotación insostenible de los recursos. La amenaza de un punto de no retorno ha dejado claro que en cuestión de recuperación de reservas haliéuticas, el simple equilibrio no bastaba. Paralelamente, estamos ante un sector en el cual el propio conocimiento científico ha tenido que madurar, pasando de un enfoque por especies a un enfoque de ecosistemas. Este último reconoce la existencia de complejas interdependencias naturales que hacen de la gestión por cuotas una peligrosa simplificación. La aparición de actores como las flotas asiáticas o la mejora de la rentabilidad de la piscicultura han modificado el panorama de la pesca en los últimos veinte años. La Unión Europea no es una potencia 
pesquera hegemónica pero sí se distinguió por haber tenido hábitos poco sostenibles que han dejado sus aguas en preocupantes condiciones.

\section{¿Cuál es la evolución del caso europeo?}

La verdadera PPC nació en 1983 cuando el Consejo Europeo adoptó el Reglamento (CEE) $\mathrm{N}^{\mathrm{O}}$ 170/83 mediante el cual se creaban las Zonas Económicas Exclusivas de reciente aparición en el derecho público internacional. La nueva gestión pesquera tenía que hacer frente a desafíos de adhesiones y retiro de cooperaciones pero impuso la idea de que se debía alcanzar un relativo equilibrio en la explotación. Ante la excedente capacidad pesquera, el Reglamento (CEE) No 3760 de 1992 reformuló la PPC de tal manera que se pudiera reducir la flota de la UE al tiempo que se establecía un sistema de licencias para la pesca. Esta reforma funcionó hasta 2002, año en el cual la UE sacó tres reglamentos que buscaron revertir el aparente fracaso de la PPC, la cual había sido incapaz de invertir la sobre-explotación de las reservas haliéuticas.

La estructuración del sector y la aceleración de la renovación de la flota marcaron esta nueva PPC que tampoco fue capaz de establecer pautas de explotación sostenibles. Como bien lo muestran Salomon y Holm-Müller (2013), la UE indujo otra reforma en el 2002 debido a los fracasos sucesivos. Esta vez, intentó aplicar una gestión a largo plazo en la cual se establecían planes de recuperación para las especies que se encontraban por debajo de umbrales que no permitieran la renovación de sus caladeros. Las ayudas al sector buscaron reducir la flota y solo invirtieron en seguridad y tecnología. Para agilizar la implementación de la nueva PPC, se creó la Agencia Europea de Control de la Pesca y para abrir la toma de decisiones más allá de las esferas de Bruselas y sus científicos, se crearon los Consejos consultivos regionales. A pesar de estas repetidas reformas, la Comisión Europea sacó a la luz en 2009 un Libro Verde en el cual propugnaba una reforma más drástica pues ninguna de las anteriores normativas había conseguido ralentizar la degradación de los medios marinos.

\section{¿Qué policy change introduce la reforma del 2013?}

Lo más relevante de la nueva PPC es que parte de una constatación común de los actores involucrados: el fracaso. Este examen pudiera parecer baladí, mas es probablemente una de las razones por las cuales los altos costos de transacción imputados por la reforma no hayan sido vistos como un impedimento al policy change. El debate entre instituciones, sociedad civil, asociaciones de pesqueros e industria ha llevado a la creación de un Fondo Europeo Marítimo y de la Pesca. Se opera pues un cambio de toda la lógica de funcionamiento. Estas modificaciones pueden ser presentadas de manera sintética en la siguiente tabla: 
Tabla 1: Resumen del perfil de las reformas de 2002 y 2013.

\begin{tabular}{|c|c|c|}
\hline & PPC 2002 & PPC 2013 \\
\hline Toma de decisión & $\begin{array}{l}\text { Centralizada con participación } \\
\text { relativa para la formulación }\end{array}$ & $\begin{array}{l}\text { Centralizada con } \\
\text { alta participación y } \\
\text { descentralización para la } \\
\text { implementación }\end{array}$ \\
\hline Principio rector & Totales admisibles de captura & $\begin{array}{l}\text { Rendimiento máximo } \\
\text { sostenible (RMS) }\end{array}$ \\
\hline Tipo de gestión & $\begin{array}{l}\text { Anual y plurianual por } \\
\text { especies sin objetivos } \\
\text { numéricos para mortalidad o } \\
\text { stock reproductor }\end{array}$ & $\begin{array}{l}\text { Plurianual ecosistémico con } \\
\text { objetivos numéricos }\end{array}$ \\
\hline Implementación & Corto y mediano plazo & A largo plazo \\
\hline Modificación institucional & $\begin{array}{l}\text { Creación de la Agencia } \\
\text { Europea de Control de la } \\
\text { Pesca }\end{array}$ & $\begin{array}{l}\text { Creación del Fondo Europeo } \\
\text { Marítimo y de la Pesca }\end{array}$ \\
\hline Capacidad flota & $\begin{array}{l}\text { Modernización y limitación } \\
\text { relativa }\end{array}$ & $\begin{array}{l}\text { Limitación anual, obligatoria y } \\
\text { proporcional al RMS }\end{array}$ \\
\hline Descartes & No controlados & $\begin{array}{l}\text { Prohibición progresiva con } \\
\text { obligación de traer a tierra }\end{array}$ \\
\hline Pesca costera & Estabilizada & Incitada \\
\hline Acuicultura & Fomentada & $\begin{array}{l}\text { Fomentada, regulada } \\
\text { y simplificada } \\
\text { administrativamente }\end{array}$ \\
\hline Datos científicos & Centralización & $\begin{array}{l}\text { Descentralización y } \\
\text { obligatoriedad }\end{array}$ \\
\hline Mercado & Estructurado & $\begin{array}{l}\text { Mayor regulación y } \\
\text { transparencia, precios } \\
\text { mínimos }\end{array}$ \\
\hline $\begin{array}{l}\text { Pesca fuera de las aguas de } \\
\text { la UE }\end{array}$ & $\begin{array}{l}\text { Controlada pero sin } \\
\text { restricciones significativas }\end{array}$ & $\begin{array}{l}\text { Controlada y con restricciones } \\
\text { para evitar pesca ilegal, } \\
\text { cambio de bandera y } \\
\text { acuerdos con países terceros } \\
\text { sometidos a criterios de RMS }\end{array}$ \\
\hline
\end{tabular}

Fuente: elaboración propia a partir de fuentes de la UE, Salomon y Holm-Müller (2013) y Carter (2013)

Sin entrar en más detalles por ahora, se puede observar que se opera una permuta de principios evidente, asimilable a un PCh al suponer igualmente el rediseño de las herramientas de la política. La inquietud que emerge tras esta presentación, es comprobar si efectivamente hay PCh y valorar su intensidad. Este cuestionamiento es aún más relevante a la luz de la ausente prohibición de la pesca de arrastre en los grandes fondos marinos. 


\section{¿Qué tipo de policy change se da en el PPC?}

$\mathrm{Al}$ revisar la literatura académica sobre el PCh se aprecia la inexistencia de propuestas claras o consensuales que establezcan tipologías del cambio en función de una jerarquización de la envergadura del mismo. Casi todos los autores, como lo recuerda Cruz (2011), debaten los modelos existentes y proponen el suyo, centrándose siempre en unos cuantos factores explicativos. Pero en definitiva, ¿̇cómo se puede saber que hay policy change? y ¿cómo se puede clasificar?

Si partimos de los aportes de Coggan, Whitten y Bennett (2010) y su noción de los costes de transacción, está claro que existe una fractura entre las explicaciones que son aportadas desde las ciencias económicas y las de la ciencia política. De hecho la contribución de Caddy y Seijo (2005) nos confirma la relevancia de los costes de transacción en la discusión del PCh pesquero:

The inherently high exclusion and transaction costs characteristic of fish resources require us to look beyond the simple solution of providing for 'proper allocation of individual rights'.

Self-policing, questions related to numbers of fishers, and issues of education are discussed

[...] as ways of mitigating these obstacles. (Caddy y Seijo, 2005, p. 70)

Si a la revisión de la literatura académica le añadimos el de la prensa y de las opiniones de actores vinculados con el sector, podemos decir que en el ejemplo de la PPC nos encontramos ante una gran variedad de factores que han sustentado el PCh: a) La constatación del fracaso de las PP anteriores para prevenir la sobrepesca; b) el alto coste financiero en un contexto de crisis económica; c) la voluntad de respetar los compromisos internacionales adquiridos; d) la modificación del panorama interno por causa de nuevas adhesiones y por ende, flotas pesqueras; $f$ ) la presencia de nuevas tecnologías que aumentan la eficacia de la pesca; $g$ ) el aumento del consumo y de las importaciones de productos derivados de la acuicultura; $h$ ) la subsistencia de prácticas difícilmente aceptables como el descarte; i) la dificultad de controlar las cuotas y la persistencia de pesca ilegal.

De esta suerte, todos estos componentes manifestados de manera tan breve, han participado en la toma de conciencia de que la PPC debía ser reformada si la UE no quiere alcanzar el punto de no retorno que ya fue experimentado en varias zonas como la costa atlántica de Canadá o la Bahía de Chesapeake. Así las cosas, es evidente que el PCh de la PPC se basó sobre un diagnóstico común y que la reforma de 2013 modifica justamente los principios rectores para la gestión de los caladeros. La alteración está igualmente en línea con lo que nombran Caddy y Seijo (2005, p. 72) como reintroducción de comedimientos éticos.

\section{¿Qué son los costes de transacción?}

La reciente disciplina de la economía ecológica ha hecho aportes sumamente reveladores que dan pistas de estudio de las cuales la ciencia política podría sacar provecho. 
Entre estos avances cabe destacar la atención puesta en el papel de los CT en la toma gubernamental de decisiones. El concepto acuñado por Ronald Coase fue enriquecido por Douglass C. North y Oliver E. Williamson, quienes lo integraron al análisis de las instituciones. Ha sido extensamente usado en el campo del análisis económico y su tímido salto a la ciencia política estuvo a cargo del enfoque de la elección racional. De hecho, uno de los primeros en proponer un análisis de las políticas públicas desde los costes de transacción fue Avinash, K. Dixit (1996). Numerosos economistas en Estados Unidos han usado la noción y son cada vez más los que lo aplican al análisis de las políticas públicas.

Alineados con la síntesis de Kerry Krutilla (2010), estimamos los CT como extremadamente útiles para advertir los incentivos en las negociaciones políticas. Los estudios centrados en las políticas públicas medioambientales (PPM) han venido de la mano de varios académicos norteamericanos, entre ellos Laura Mc Cann, una de las primeras en proponer una clara tipología para los CT (Laura McCann y Easter, 2004). La omnipresente preocupación por la cuantificación de muchos de los autores está confrontada a límites prácticos en el caso del análisis político.

A pesar de las propuestas heurísticas de Mc Cann (McCann y Easter, 1999) y de Pannel et al (Pannell, Roberts, Park, y Alexander, 2013), sigue siendo una tarea bastante complicada, sobre todo cuando se trata de evaluar los CT ex ante (antes de la decisión). Así las cosas, los CT permiten tomar conciencia de que la decisión política está sometida a unos condicionantes que van mucho más allá de la ideología o revisión de alternativas.

Expuestas las limitaciones, se debe especificar que el concepto resulta útil a la ciencia política por varias razones. Primero, está claro que los costes inducidos por la búsqueda de datos, la negociación y la implementación pueden frenar ciertas PP. Segundo, los CT son una variable que se da en cualquier negociación política. Tercero, la información incompleta, la incertidumbre, el oportunismo y la gran diversidad de opiniones hacen que la formulación de las políticas dependa de estrategias de los actores para influenciar en los montos y repartición de los CT.

No hay duda de que la aplicación del concepto a la ciencia política es problemática y polémica. A expensas de sus límites, resulta enriquecedor, sobre todo el institucionalismo institucional que, como bien lo resume Caballero Míguez (2007, p.21), “[...] emerge a partir del institucionalismo de elección racional, y a través de la incorporación de lecciones procedentes de la nueva economía institucional y de un diálogo más fluido con el institucionalismo histórico". En este trabajo entendemos los costes de transacción de acuerdo a la definición de Laura McCann y Easter (2004), definición que es empleada en toda la literatura para su aplicación del concepto a las PPM. No hay que olvidar que esta definición es incluso retomada por Coggan et al. (2010) así como Marshall (2013), los cuales adoptan un enfoque crítico pero continuista de la disciplina. 


\section{Hipótesis de explicación del policy change desde los costes de transacción}

Una vez aclarada la noción, podemos pasar a enunciar nuestra hipótesis en relación al caso de la PPC. A nuestro parecer, el PCh se daría porque los costes de transacción ya eran tan elevados que una nueva PPC no inducía desacuerdos que fueran política ni económicamente viables. Si generalizamos la conclusión, la hipótesis ampliada sería: el policy change se da cuando existen bajos o muy altos niveles de costes de transacción. La mayoría de las negociaciones medioambientales supondrían un aumento progresivo de los CT a través de la replicación del incrementalismo. Llegado un cierto momento del path dependence, los CT serían tan altos que inducirían una reducción de la utilidad marginal del desacuerdo.

Para poder entender si estas franjas de oportunidad existen, se debe examinar las trayectorias de la complejidad de formulación y diseño así como la distribución de los CT. En este marco de pensamiento, las estrategias desarrolladas para mitigar los costes de transacción cobrarían entonces especial relevancia (Caddy y Seijo, 2005, p69).

En definitiva, las tesis enunciadas en este texto buscan desgranar esta teoría del cambio sin instituir una justificación de los mismos pues se debería llevar a cabo un amplísimo trabajo empírico de terreno y documental para comprobarlas. Pasamos entonces a enumerar nuestra cavilación sobre la base de diez tesis cuyo objetivo es ayudar a entender el policy change a partir del caso de la PPC.

\section{Tesis 1: Los costes de transacción ayudan a explicar el policy change inducido por los modelos del desarrollo sostenible, de la modernización y de la democratización ecológicas}

Comenzamos nuestro análisis con la revisión de los tres principales modelos que han tratado de implantar la ecología en el seno de la decisión política. En primer lugar está el desarrollo sostenible (DS) que según Jeffery (2005), es el enfoque que mejor se adapta a las nuevas consideraciones éticas, su maduración paralela a la progresión de los valores habría justificado la predilección de los organismos internacionales por este discurso. El DS ha tenido éxito al traer a las políticas públicas: a) la difusión e implementación de las evaluaciones de impacto medioambiental; b) la ampliación de la protección sobre áreas naturales (entre ellas las relacionadas con comunidades indígenas).

El gran optimismo que generó el enfoque del DS en la década de 1980 se puede contrastar con el pesimismo que cosecha actualmente. En efecto, la constatación de la insuficiencia de las políticas nacidas a partir de su enunciación llevó a los ecologistas y académicos a buscar un enfoque más ambicioso. Es de notar que además de su instrumentalización, existe la dificultad para su operacionalización o trasposición a la práctica. Clini, Musu, y Gullino (2008) han tratado de elaborar una reflexión sobre el caso Europeo con el fin de saber qué faltaba para completar la transición plena al DS. Estos autores llegan a la conclusión de que en la UE se echan en falta dos líneas de trabajo para facilitar 
la transición: 1) se tiene que integrar la dimensión medioambiental en todas las políticas públicas sectoriales; 2) se tiene que favorecer la iniciativa de grupos e individuos. Estos autores llegan pues a la conclusión de que es esencial crear incentivos económicos para que el consumidor modifique sus comportamientos o hábitos.

La lógica detrás de esta intuición sería que una vez constatado el cambio en los hábitos, los productores modificarían su oferta hacia un modelo más sostenible. Como se ve, el DS reposaría entonces sobre principios económicos y no políticos, donde se confía en los ajustes del mercado. La responsabilización del consumidor, que ha sido sugerida en la PPC de 2013, se ve confrontada a la otra vía, la de la responsabilización del productor, defendida, entre otros por Deutz (2009). En el caso de la PPC existe precisamente una actuación en estos dos sentidos, además de un cambio institucional en los términos defendidos por Birner y Wittmer (2009).

A la luz de los CT el discurso del DS tendría capacidad para generar PCh. Yendo más en detalle, considerando el aporte de Birner y Wittmer (2009) sobre los beneficios y costos de los actores involucrados en las políticas públicas medioambientales, se hace latente que la verdadera pregunta es otra. No nos importa únicamente si el desarrollo sostenible como modelo genera policy change, sino más bien si nos ayuda a explicar por qué no se da. A este nivel el discurso es claramente propositivo y termina confiando en que la simple modificación del enfoque económico puede generar cambios. De hecho la conclusión de Brand (2010) según la cual el PCh en este enfoque solo modifica la intensidad de la explotación medioambiental deja claro que solo se busca inducir el PCh sin entenderlo.

A este nivel la existencia de discursos claramente contradictorios (Boutilier, 2005) sería una pista de la inconsistencia a largo plazo. Así pues, con la mira puesta en nuestra hipótesis, podemos intuir que el desarrollo sostenible induce cambios inestables en la intensidad y repartición de bajos costos de transacción, donde la complejidad de la formulación de las políticas seguiría siendo limitada. La evolución de la diversidad y complejidad de los entramados normativos tanto internacionales como europeos de la política pesquera (Pastoors, 2014) podrían mostrar precisamente que el DS induce tres momentos bien claros: 1) una toma de conciencia que genera una política pública disruptiva; 2) una vez instalados los principios del desarrollo sostenible, se caería en el incrementalismo; 3) en el tercer periodo, se daría una puesta en duda de la trayectoria de las políticas del DS. En esta se generaría justamente la reversión de la tendencia, es decir la aparición del PCh.

La evolución histórica de la PPC se amolda perfectamente a esta trayectoria, tanto en sus ramificaciones normativas como en sus resultados. Huelga decir que enunciamos este discernimiento porque un análisis superficial de otros sectores deja entrever, a primera vista, trayectorias similares.

El segundo enfoque, la modernización ecológica (ME), está ligado a la voluntad del ecologismo de superar las herramientas económico-centristas e inducir precisamente 
un policy change. El planteamiento central es la revisión de los principios éticos generadores, además de una implementación con metas más radicales. Paradójicamente, no siendo el planteamiento más conocido por la ciudadanía, este enfoque está mucho más presente en la investigación académica que aquel del desarrollo sostenible. Puede que esta diferencia esté fundamentada en la desnaturalización del desarrollo sostenible y su escasa reflexión sobre el PCh para su éxito. De hecho, el enfoque de la ME ya no parte de una lógica estrictamente de desarrollo, pues supedita la dimensión ecológica a la reformulación de ciertas prácticas sociales. Esto supone que el cambio se tiene que acompañar por una capacidad de las políticas públicas para considerar de manera seria y automática la dimensión medioambiental más allá de los impactos económicos.

Numerosos autores coinciden en establecer la dicotomía según la cual la modernización ecológica es tanto un modelo teórico como una propuesta para la acción. Berger, Flynn, Hines y Johns (2001), defendiendo la lectura ideológica y política de los dos enfoques (desarrollo sostenible y modernización ecológica), hablan de esas dos dimensiones. Tendríamos: a) el modelo como framework (marco) destinado a analizar los cambios de las instituciones y; b) el modelo como guía para la formulación de políticas públicas.

Estos mismos autores definen la propuesta de la modernización ecológica como multifacética. Esta incluiría: a) la defensa del ajuste tecnológico; b) una renovación del sistema de creencias; y c) un discurso de políticas que trata de subrayar el papel de la prevención. Todas estas dimensiones guardan relación con los costes de transacción a través de la modificación de las bases del planteamiento. No en vano, numerosos estudios ligan de manera directa el concepto del riesgo de Ulrich Beck con la modernización ecológica. Esta relación nos deja latente que la prevención y la evaluación del coste de oportunidad implementada en todas las PP modifica per se el monto de los CT en los procesos de decisión. Baste solo mencionar que si la ME es tomada en serio, esta supondría un aumento en tiempos, investigaciones científicas para fundamentar el principio de precaución, medidas para la participación, estudios sobre el impacto ambiental, etc.

Es pues sustancialmente revelador que el enfoque de la ME genera de facto en su aplicación, un aumento de los costes de transacción, aun cuando su objetivo no sea el policy change per se. He aquí de hecho una paradoja inesperada. En efecto, la ME busca que todas las políticas consideren la dimensión ambiental, mas eso no supone forzosamente inducir PCh. Inclusive la premisa de la ME no es explicar el PCh sino solamente sistematizar un cierto procedimiento en la toma de decisiones.

Si partimos de la ME desde los CT, podemos enunciar una clara limitación del enfoque para generar PCh. Se daría un aumento en los CT, mas este proceso no estaría acompañado por una redistribución, sobrecargando las instancias públicas en vez de hacer copartícipes a los actores privados. Estamos ante un discurso que identifica el limitante del PCh en un nivel básico: ausencia de sistematización de la toma en consideración del ambiente. Sin embargo 
la solución de la sistematización no considera el hechojustificador del limitante, a saber, por qué no se integraba de manera sistemática la dimensión medioambiental en las políticas.

$\mathrm{Al}$ proponer un remedio mono-dimensional, la ME plantea una solución que dejaría de lado esa redistribución de los costes de transacción. Es más, la visión del propio Arthur P.J Mol (2000) sobre la integración de la ME al discurso de los movimientos ecologistas presenta un panorama que sustenta esta conclusión. Según este autor, la unificación de muchas posiciones divergentes bajo una misma bandera ha abierto más ventanas de oportunidad para incidir en las PP. La existencia del discurso cohesionador permitiría presionar las instancias públicas para que modifiquen los costes de transacción (más participación, investigación etc.) empero esos mismos movimientos no participan en los nuevos gastos generados. Baste a este fin, esgrimir la realidad de muchas entidades públicas, que han tenido que contratar evaluadores ambientales puesto que las organizaciones no gubernamentales ecologistas (eONG) no han suplantado actores profesionales, limitándose a ejercer tareas de monitoreo.

En todo caso, la conclusión de Memon, Kirk, y Selsky (2011) sobre el estudio de caso de la gestión del agua en Nueva Zelanda tal vez sea más directa y propugne una respuesta sencilla: la modernización ecológica permite mejorar la gestión pero no genera PCh. Podríamos añadir que la ME falla también a nivel de la automatización. Paralelamente, el análisis de Murphy y Gouldson (2000) concluye que la ME es incapaz de sistematizar o forzar la adopción de las nuevas soluciones técnicas por parte de las industrias. Esa falla en la sistematización así como la ausente repartición de los costes de transacción sería lo que explicaría una mayor presencia del policy change en Europa que en Estados Unidos, donde pervive una perspectiva conservacionista de la ecología (Cohen 2006). En el caso de la UE, la ME aumentaría los CT y la repartición de los CT se haría de manera indirecta, al derivar la UE parte de sus cometidos en los países miembros. No obstante esta repartición se haría de facto entre instituciones públicas y la implicación del sector privado no es ni obligatoria ni la misma entre los países del conjunto.

Hemos visto pues que este segundo enfoque de la ME contendría igualmente limitantes inherentes a su diseño para generar el policy change. Si pasamos a la tercera propuesta que nos ocupa, el discurso de la democratización ecológica (DE) trata justamente de ir más allá. Connelly y Smith (2003) argumentan que se busca una modificación institucional que permita la introducción de la deliberación para: a) hacer frente a altos niveles de complejidad e incertidumbre en la resolución de los problemas colectivos; b) promover y articular las preferencias y los juicios sobre la base de dimensiones públicas; c) la activación y conservación de la noción de ciudadanía a partir de la cual refundar la socialización y percepción de los desafíos como sociedad.

Si comparamos la aparición de este discurso con la nueva puesta en duda de las políticas tradicionales, nos percatamos de que la nueva repartición de los CT que operaría 
la ME sí que facilitaría el PCh. Más concretamente, la DE daría el paso que le faltaba a la ME, a saber la repartición del aumento de los CT entre actores privados y públicos, de tal manera que las instituciones no fueran las únicas que tuvieran que lidiar con esa modificación. Esta conclusión sería consistente con la categorización que hacen Caddy y Seijo (2005, p. 69) de los costes de transacción, pues tendríamos costes de exclusión, costes de información y costes de implementación.

En el caso de la PPC, se podría asimilar el amplio programa de consulta, participación y probable regionalización con una tentativa de pasar de la ME a una tímida DE. $\mathrm{El}$ aumento de los CT sería compensado por una repartición inexistente bajo el modelo de la ME. Tomando todos los elementos explicativos enunciados hasta ahora sobre los tres enfoques y poniéndolos en paralelo con el caso de la PPC, podríamos presentar las explicaciones bajo la forma de la siguiente tabla.

\section{Tabla 2: Perfil de los modelos en función de las variables y resultados}

\begin{tabular}{|l|l|l|l|}
\hline \multicolumn{1}{|c|}{ Acción \Modelo } & \multicolumn{1}{|c|}{$\begin{array}{c}\text { Desarrollo } \\
\text { Sostenible }\end{array}$} & \multicolumn{1}{c|}{$\begin{array}{c}\text { Modernización } \\
\text { ecológica }\end{array}$} & $\begin{array}{c}\text { Democratización } \\
\text { ecológica }\end{array}$ \\
\hline $\begin{array}{l}\text { Aumento costes de } \\
\text { transacción }\end{array}$ & Bajo & Alto & Alto \\
\hline $\begin{array}{l}\text { Repartición de los } \\
\text { costes de transacción }\end{array}$ & Medio & Bajo & Alto \\
\hline $\begin{array}{l}\text { Complejidad } \\
\text { formulación }\end{array}$ & Medio & Alto & Alto \\
\hline Policy change & Probable pero aislado & $\begin{array}{l}\text { Improbable e } \\
\text { inestable }\end{array}$ & $\begin{array}{l}\text { Probable pero } \\
\text { paradójico }\end{array}$ \\
\hline Política pesquera & Reforma 1983 & Reforma 1992 & Reforma 2013 \\
\hline
\end{tabular}

Fuente: elaboración propia

\section{Tesis 2: La literatura sobre el policy change explica alicientes y no limitantes}

Siguiendo con la línea del análisis de los CT en los tres enfoques dominantes (DS, ME y DE) podemos profundizar poniendo en relación directa los puntos enunciados anteriormente con la literatura académica del policy change. Esta última está estrechamente ligada, como bien lo dice Parsons (2007), al enfoque procesal de las políticas públicas que ha dominado la disciplina durante más de veinte años. Sin embargo hoy en día se puede considerar la noción independientemente de la aceptación o no del policy process gracias a la puesta en duda llevada a cabo por autores como Sabatier y Jenkins-Smith (1993). A la luz de la PPC y de nuestro análisis anterior, las críticas desarrolladas por Howlett y Rayner (2006) sobre las metodologías de la disciplina cobran todo su sentido. Es evidente que son pocos los autores que han verificado la validez de sus propuestas teóricas sobre la base de casos. 
La primera conclusión que podemos adelantar es que los modelos son contextuales y desarrollan explicaciones sobre los alicientes del cambio sin interrogarse sobre los limitantes. Como lo hemos explicado en la introducción, la segunda dimensión del cuestionamiento se torna esencial para concebir la ausencia de cambios más radicales en las políticas públicas. Por todo ello podríamos sugerir la incapacidad desde los enfoques teóricos de Ostrom, Kingdom, Sabatier o Jones y Baumgartener para explicar la ausencia del policy change. Estos permiten entender la evolución de ciertas políticas pero soportan mal la generalización.

La gran ventaja de una reflexión que partiría de los costes de transacción residiría en que los TC se dan tanto en presencia como ausencia de PCh. Es decir, estamos ante una noción que permitiría analizar todos los casos de políticas desde sus dos criterios inmediatos, a saber monto y repartición de los TC. Todas las propuestas teóricas ofrecen una relación con los CT sin analizarlos. Es más, la clasificación de las teorías que establece Wayne Parsons (2007) en cuatro corrientes teóricas ${ }^{3}$ responde igualmente a modificaciones en los montos y reparticiones de los CT. Si retomamos los principales autores así como sus puntos de incidencia del cambio y los ponemos en relación con los tres enfoques analizados aquí, podríamos establecer la siguiente relación.

\section{Tabla 3: Las teorías del policy change frente a los tres enfoques}

\begin{tabular}{|l|l|l|l|l|l|l|l|l|}
\hline Autor & Kingdom & $\begin{array}{l}\text { Jones y } \\
\text { Baumgartner }\end{array}$ & $\begin{array}{l}\text { Marsh y } \\
\text { Rhodes }\end{array}$ & Sabatier & $\begin{array}{l}\text { Ingraham y } \\
\text { Schneider }\end{array}$ & Wilson & Ostrom & $\begin{array}{l}\text { Otros } \\
\text { autores }\end{array}$ \\
\hline $\begin{array}{l}\text { Punto de } \\
\text { incidencia } \\
\text { del cambio }\end{array}$ & $\begin{array}{l}\text { La } \\
\text { decisión } \\
\text { política }\end{array}$ & $\begin{array}{l}\text { La imagen } \\
\text { política }\end{array}$ & $\begin{array}{l}\text { El contexto } \\
\text { de la } \\
\text { política }\end{array}$ & $\begin{array}{l}\text { Los } \\
\text { sistemas de } \\
\text { creencias }\end{array}$ & $\begin{array}{l}\text { Las } \\
\text { construcciones } \\
\text { sociales }\end{array}$ & $\begin{array}{l}\text { El régimen } \\
\text { de la } \\
\text { política }\end{array}$ & $\begin{array}{l}\text { Acuerdos } \\
\text { institucionales }\end{array}$ & $\begin{array}{l}\text { Diseño/ } \\
\text { formulación } \\
\text { de la } \\
\text { política }\end{array}$ \\
\hline DS & $\mathrm{X}$ & $\mathrm{X}$ & & $\mathrm{X}$ & & & & $\mathrm{X}$ \\
\hline ME & $\mathrm{X}$ & & $\mathrm{X}$ & & & & $\mathrm{X}$ & $\mathrm{X}$ \\
\hline $\mathrm{DE}$ & $\mathrm{X}$ & $\mathrm{X}$ & & $\mathrm{X}$ & $\mathrm{X}$ & $\mathrm{X}$ & $\mathrm{X}$ & $\mathrm{X}$ \\
\hline
\end{tabular}

Fuente: elaboración propia sobre la base de Cruz (2011)

\section{Tesis 3: El encuadre positivo de la política pública ayuda a la repartición de los costes de transacción}

En la lectura política de los problemas medioambientales subsiste un encuadre (framing) que posiciona al ser humano por fuera de la naturaleza (Dylan, 2012) y de hecho los términos sostenible y sustentable ligados al DS reproducen un acercamiento que infravalora el desafío ecológico y deposita excesiva confianza en la técnica. La manera en la cual formulamos el problema ecológico influencia la toma de decisiones. Como lo sugiere la teoría desarrollada por Tversky y Kahneman (1981), el encuadre de las contingencias

\footnotetext{
${ }^{3}$ 1) Redes y comunidades de políticas públicas; 2) corrientes de políticas públicas; 3) coaliciones promotoras y 4 ) equilibrio interrumpido.
} 
y de los resultados ligados con el problema y su solución llevan a reacciones diferentes en los negociadores. En nuestro caso, la distinción más clásica entre una formulación en positivo y en negativo, puede que haya tenido consecuencias sobre el PCh en el caso de la PPC. Es decir, el consenso sobre el fracaso de la lógica de las cuotas de las reformas anteriores puede que esté también ligado con la formulación del problema. En efecto, la normativa de la nueva reforma de 2013 presenta la prohibición del descarte como una manera de salvar miles de peces que actualmente son víctimas de una pesca insuficientemente selectiva. Antes, las cuotas querían evitar la desaparición de los caladeros. Es decir, estábamos ante un encuadre negativo. A partir de la reforma de 2013 estamos en una lógica, inducida por el acercamiento eco-sistémico, en la cual se quiere salvar los caladeros. Es una cosa bien distinta pretender evitar la desaparición a salvar.

Aunque no dispongamos de una evidencia empírica sobre esta cuestión, pues se necesitaría hacer un análisis de los discursos que se dieron durante las rondas participativas entre 2009 y 2013, intuimos que el acuerdo sobre el fracaso ha generado una perspectiva positiva hacia la problemática derivada del hecho según el cual el fracaso de las PPC anteriores se podían también achacar a un acercamiento coercitivo y simplificador. Puede que esta conmutación se relacione con el contenido de la crítica que hace Aitken (2012) al afirmar que en la discusión sobre el cambio climático se da una despolitización en las PPM y que estamos ante limitaciones relacionadas con presupuestos modernistas.

La predominancia de los científicos hasta la reforma del 2013 de la PPC puede corresponder a este factor, puesto que según Aitken las preferencias de los actores involucrados en la toma de decisiones están condicionadas por tres elementos: 1) el encuadre, que vendría determinado por los intereses económicos; 2) la agenda determinada por la élites políticas y; 3) cómo los individuos perciben sus intereses y preferencias afectados por las relaciones de poder no claras.

En el debate del cambio climático, el encuadre es positivo y sirve para justificar una gran panoplia de políticas. De hecho, como lo sugiere Aitken, se habla de asegurar el aprovisionamiento energético o diversificar sus fuentes empero en muy menor medida de la reducción del consumo. De la misma manera que en el caso del cambio climático, el encuadre tiene un efecto, podemos imaginar en el caso de la PPC, las instancias europeas han dado un paso hacia las formulaciones positivas. Esto se torna más claro si consideramos el discurso sobre las inversiones en las fuentes de energía renovables.

Así las cosas, podemos imaginar que el tipo de encuadre también tiene consecuencias sobre la repartición de los CT, pues los actores vinculados a la toma de decisiones tienen un acercamiento distinto a sus beneficios y pérdidas. Este tipo de sesgo cognitivo probablemente esté igualmente ligado con el papel del issue linkage que según Eugénia da Conceição-Heldt ( 2008) se ha dado en las negociaciones pesqueras. De hecho, la conclusión de esta autora sobre la necesidad de dos grupos principales que perciban 
beneficios superiores a los costes con el freno de la aversión a las pérdidas sugiere que estamos precisamente ante una repartición de CT. Es más, Conceição-Heldt (2006) sugiere, al analizar las negociaciones de las PPC sin casarse con ningún modelo, que los gobiernos más débiles tienen reticencias para firmar acuerdos y estos se verían doblegados por las concesiones efectuadas por las otras partes negociadoras.

Estaríamos en el caso de las PPC ante contextos en los cuales los actores prefieren el acuerdo a la ausencia de este, donde asimilan el coste del cambio como inferior al de no cambiar. En este caso pues, los CT serían ya muy altos y los actores conscientes de que podían reducirlos tanto a través del cambio de los principios de la política o reasignándolos. Finalmente tal vez - pues sería de muy difícil verificación- el efecto del encuadre esté relacionado con la mayor propensión al policy change en el caso del desarrollo sostenible y de la democratización ecológica pero no de la modernización ecológica.

\section{Tesis 4: Los costes de transacción permiten diferenciar los cambios coherentes y los cambios de 'fachada'}

Hoy en día muchas políticas tienen una dimensión claramente simbólica (Stone, 2001) y hay que presuponer que ciertos cambios en las políticas públicas son anunciados pero no aplicados. Estaríamos en este caso ante cambios de 'fachada' o cambios nominales cuyo contenido se vaciaría a la hora de la implementación. Una de las ventajas de la noción de los TC sería que permite analizar las PPM más allá de la simple formulación e implementación. Al poner en paralelo las PPM con la estructura de toma de decisión, las herramientas y costes de la implementación, se podrían detectar los PCh inconsistentes o aparentemente inviables en razón de la ausencia de la modificación en la estructura o montos de los costos de transacción. Este punto necesitaría obviamente mucha más investigación y por ende una medición de los CT. No obstante, partiendo de nuestra hipótesis central, es más que probable que la cantidad y la repartición de los CT puedan servir para dos fines. Primero, detectar los cambios de políticas nominales (que se quedan en el papel y no pasan a la implementación). Segundo, ayudar a predecir con todas la salvedades que pueda haber, la posibilidad de un policy change en contextos similares a los que se dan cuando los CT son muy altos o muy bajos y existe una modificación en la repartición de los mismos.

\section{Tesis 5: La complejidad de la formulación refleja e impacta los costos de transacción}

No hay muchos textos que estudien la influencia de la complejidad en las políticas públicas. Concretamente, los aportes bajo este enfoque no están cerrados del todo, dejando los autores simplemente la inquietud de la aplicación de la teoría de la complejidad a la toma de decisiones. Boulton (2010) explora las implicaciones de la complejidad para los formuladores de políticas públicas y concluye que los decisores deben de lidiar con las contradicciones e inconsistencias. Sus principales conclusiones son las que siguen (2010, p. 39): 
1) La economía se inserta en la sociedad a través de un marco político que impacta la sostenibilidad y la justicia social. Los decisores deberían dejar claro qué responde a objetivos económicos, sociales, de seguridad o de sostenibilidad en conocimiento de escalas de tiempo. 2) El pensamiento sobre la complejidad ayuda a comprender que las políticas casi nunca se desarrollan como se habían planeado por lo que los decisores y sus estructuras institucionales deben de ser capaces de adaptarse a contextos cambiantes. 3) Los mercados tienden a concentrar el poder en pocas manos y la disminución de la diversidad necesita regulación contra-tendencial. 4) Los desafíos económicos, sociales y medioambientales traspasan las fronteras de la regulación y las políticas no. Hay pues que actuar sobre los entes que tienen capacidad trasnacional, entre ellas las grandes multinacionales.

Las conclusiones avanzadas por Boulton no se focalizan en la complejidad de la formulación o diseño de las PPM pero sí dejan entrever que la clave está en la capacidad de adaptación. Si retomamos su primera conclusión, el anuncio hacia dónde se va podría estar relacionado con las estrategias de negociación de los actores vinculados a las políticas públicas. La segunda aseveración resalta la capacidad de adaptación frente a contextos cada día más cambiantes. La tercera afirmación hace énfasis en la necesidad de abrir la toma de decisiones y su cuarta enunciación subraya la necesidad de implicar las organizaciones que tienen responsabilidad y capacidad (incluidas las del sector privado).

Si leemos bien entre líneas estas conclusiones, todas están relacionadas con la repartición de los CT. Aunque no se pueda establecer por el momento una relación de causalidad, la toma en cuenta de la complejidad en los procesos políticos permitiría generar estrategias para la repartición de los costes de transacción. Podríamos aventurarnos a sugerir que la insuficiente adaptación a la complejidad se da en el incrementalismo, donde se evita el PCh en razón de una ausencia de estrategias eficaces para lidiar con la complejidad más allá de la vía conservadora lindblomiana. En el caso que nos ocupa de la PPC, Pastoors (2014) relaciona en un curioso artículo la complejidad de la misma con el número de palabras usadas en las normativas. Partiendo de ese enfoque -eso sí, por lo poco algo simplistanos sugiere que la PPC ha conocido una escalada en la complejidad de la formulación.

Es cierto que las PPC han ido completando poco a poco terrenos de acción que antes estaban desregulados. Sin embargo las normativas relacionadas con la PPC buscaron, como lo sugieren los propios documentos de la Comisión y del Parlamento Europeo a través del libro verde de 2009, una simplificación de las PPC. De hecho, todos los actores involucrados en la PPC hicieron especial hincapié en este asunto durante las consultas de la última reforma. La pregunta es pues si el hecho de tener más palabras significa que la PPC sea más compleja. Desde un punto de vista politológico y analizando los textos de la reforma de 2002 frente a la de 2013, es difícil argumentar un aumento en la complejidad. Las cuotas y las lógicas de funcionamiento han sido simplificadas a nivel de la UE puesto que delegan parte de sus funciones a los Estados 
miembros. Lo sorprendente es que a pesar de partir de principios en primicia más fáciles de aplicar, el PCh inducido lo ha sido gracias a la aparición de excepciones en el descarte que supuestamente iba a ser prohibido en su totalidad.

Lo que está claro es que el texto de la PPC de 2013 buscaba una simplificación y que en cierta medida lo ha conseguido gracias a precisamente, la delegación de ciertas funciones regulatorias y de monitoreo en manos nacionales. Se podría pues ligar la bajada de la complejidad -aunque muy relativa, eso sí- con la repartición de los costes de transacción. Es por lo pronto interesante lo que nos sugieren Hadjimichael, Edwards-Jones y Kaiser (2010, p. 801) al afirmar: "A simplified regulatory framework with different methods of governance allowing a greater involvement of stakeholders and a fast-track decision-making process are essential in a rapidly evolving sector such as fisheries."

Según estos autores la complejidad de la PPC de 2002 supuso una reducción de la traída a tierra de descartes, puesto que los pescadores no querían correr riesgos de ser penalizados por prácticas que eran de difícil detección en la mar y cuyas pruebas no querían proporcionar. Lo que está claro es que la complejidad normativa de la PPC ha ido regulando el sector al tiempo que este ha ido teniendo cada vez menos capturas.

En resumidas cuentas podríamos asimilar la insuficiente adaptación con el incrementalismo y el policy change con la apertura de la decisión. Justamente en el ejemplo de la PPC, esta complejidad fue acompañada por la constatación de las autoridades de su incapacidad para hacer respetar la norma. A este nivel podemos tener en cuenta la conclusión de Elgie y McMenamin (2005) según los cuales cuando se presentan casos de alta complejidad reguladora y se necesita una respuesta creíble, se tiende a la creación de autoridades administrativas independientes. Siguiendo esta línea, resulta manifiestamente evocador que el PCh en el contexto de la PPC, se diera de manera paralela a la aparición de dos nuevas instituciones europeas. Lejos de ser una coincidencia, el rediseño institucional permitiría una repartición de los costes de transacción tanto ex ante como ex post. Para terminar, se puede sin duda relacionar la modificación del organigrama institucional con el enfoque de la democratización ecológica, que justamente propugna por una modificación de las estructuras ligadas a la toma de decisión con el fin de integrar todos los actores principales.

\section{Tesis 6: Los costes de transacción soportados por los actores privados modifican pero no condicionan el policy change}

Los procesos de participación implementados para generar la reforma de la PPC de 2013 duraron más de tres años. Hatchard y Gray (2014) han examinado las consecuencias de la integración de los Consejos consultivos regionales en la toma de decisiones. Estos órganos, más conocidos bajo sus iniciales en inglés RACs, introducían la sistematización de la participación de la sociedad civil en el debate: eONGs, científicos, ciudadanos, pesqueros, industrias, etc. Según Hatchard y Gray la participación ha ayudado a aumentar la confianza 
de los actores en la PPC y modificó la creencia entre la ciudadanía de que estamos ante una mera política decidida por los científicos. Los RACs, financiados por la UE, habrían servido pues para transmitir la buena disposición de las instancias de la UE para alcanzar una PPC que tuviera en cuenta todos los puntos de vista y dejara de lado los principios hasta entonces propugnados con la sola justificación científica. Intuimos que dicha participación ha supuesto mayores costes de transacción pero estos han favorecido también una mayor aceptación por parte de los actores privados de su responsabilización, lo cual a fin de cuentas los predispone para seguir vinculados a la hora de implementar la PPC.

La repartición de los CT expost será más que probable en un contexto en el cual la nueva PPC pretende delegar tareas de decisión, control y monitoreo a escala local o nacional. El impacto del diseño institucional vinculado con la toma de decisión y la implementación ha sido ampliamente documentado en la literatura. No obstante la participación es un fenómeno reciente cuyos resultados no son siempre tan uniformemente aplaudidos. Un ejemplo sería la crítica de Fine y Owen (2005), quienes argumentan que la obligación legal de abrir espacios de participación es paradójica habida cuenta de la gran dificultad que entraña la comprensión de los problemas. La menor presión ciudadana en razón de la baja participación llevaría a decisiones menos ambiciosas. En el caso de la PPC podríamos contradecir esta perspectiva pues entre 2009 y 2013 se dio una fuerte participación. Esta no se desarrolló a expensas de la ciencia sino que justamente la UE trató de establecer un diálogo donde los pescadores y los científicos complementaran mutuamente sus análisis, generando un debate que no estuvo limitado por el tecnicismo. Precisamente, es probable que en el caso concreto de la PPC la reforma haya sido capaz, a través de la participación, de preparar la descentralización de tareas como la investigación.

No en vano McKinney y Kemmis (2011) sugieren que la colaboración, representación, deliberación y participación generan decisiones más informadas. Sin caer en triunfalismos o visiones excesivamente positivas, no hay duda de que un proceso consultivo y participativo de tres años pueda responder a este perfil. Sorprendentemente y como lo argumentan Coggan et al. (2010), son pocos los estudios sobre los TC que hayan integrado los actores privados en el análisis. Así las cosas, vemos que en este caso los procesos abiertos sugieren un papel relevante que no se puede dejar de lado.

\section{Tesis 7: la convergencia ética reduce los costos de transacción y la ética ambiental no es funcional para este fin}

Se puede sugerir que a una mayor convergencia sobre los valores que fundamenten una política más se favorece un resultado ambicioso. Las desavenencias sobre los principios éticos harían aún más difícil el acuerdo para generar un cambio en las políticas. Aunque por detrás de esta cuestión de la ética subyace la problemática de la legitimidad (Ungaro, 2005), el papel de la ética entre los decisores es de difícil documentación. La 
clara revisión de la literatura sobre la ética medioambiental efectuada por McShane (2009) nos sugiere dos reflexiones principales.

Primero, no existe hoy por hoy una verdadera convergencia en los principios y valores entres los actores que diseñan las políticas públicas. Jayal (2001) va más lejos y sugiere la existencia de factores que crean tensión para compatibilizar los valores de la política y de la ecología. Sea así o no, en la PPC existió un cierto consenso sobre el diagnóstico y la necesidad de la preservación de los caladeros. Lo que no ha habido es una justificación que unifique a todos los actores: los unos defienden la biodiversidad marina per se y otros lo hacen por sus implicaciones económicas y sanitarias. Sea cual fuere el enfoque, en la reforma de 2013 se habría dado precisamente un PCh en razón de una convergencia a la hora de ver la preservación del medio marino como un valor. En los casos donde hay, como en la PPC, una cierta cohesión en la lectura de lo que tiene valor, la cantidad y distribución de los CT se harían de manera más consensual. La PPC de 2013, al plantear la posible regionalización y delegación de tareas, vincula los actores públicos y privados, haciéndoles partícipes de la aplicación de la visión ética que generó la política.

Nuestra segunda reflexión en este ámbito profundiza la enunciación anterior. Más allá de la convergencia, está claro que hoy día el discurso ético medioambiental (que ha ido construyéndose desde hace un siglo, principalmente a partir de los aportes ecologistas norteamericanos) no facilita ni impregna las argumentaciones políticas de los decisores. Al hacer una revisión de las bases de datos del Ministerio de ecología francés así como las instituciones europeas (Parlamento y Comisión), podemos constatar que casi ningún documento menciona de manera expresa la ética medioambiental. Es decir, este instrumento teórico ha fallado para lo que más podía servir, a saber facilitar la convergencia ética. La ética medioambiental (tanto antropocéntrica como ecocéntrica) no ha permeado los discursos políticos y se reduciría así la posibilidad de inducir PChs más recurrentes. La explicación de este fracaso reside más que probablemente en la mala vertebración de esa nueva propuesta ética.

\section{Tesis 8: El financiamiento de la ciencia influencia los costes de transacción}

Las políticas pesqueras son verosímilmente unos de los campos por excelencia donde la acción ha estado supeditada a la incorporación de los científicos a la toma de decisiones. Si revisamos el papel de estos en las políticas públicas a la luz de las conclusiones sacadas por Irvine (2009), entendemos que los expertos deberían aplicar el principio de precaución, ser transparentes y comunicativos. La gran dificultad para la ciencia a la hora de establecer causalidades y predicciones ha justificado la inacción durante muchos años. Y sigue siendo, en cierta medida, lo que sucede con el cambio climático. Este es recurrentemente puesto en duda por una ciencia politizada que no tiembla en ir en contra del último reporte del 
Panel intergubernamental sobre el cambio climático (IPCC), que en 2013 dejó pocas dudas sobre el origen antrópico del problema. En todo caso, la ignorancia humana no supone en ningún caso la ausencia de causalidades o inexistencia del problema.

El caso de la PPC es tal vez paradigmático, puesto que la omnipresencia de los científicos es precisamente la que ha sido cuestionada. Su certeza ha llevado a la reacción contraria, a saber ignorar los avisos de la comunidad científica. El ejemplo de las cuotas que han sido asignadas entre 2002 y 2009 por encima de los mínimos aconsejados por los científicos lo demuestra. Como bien lo manifiesta Brint (1990), existe una progresiva politización de la ciencia así como un empoderamiento de los científicos cuyo papel ya no puede ser catalogado en sus cuatro categorías ${ }^{4}$. No en pocos casos el debate pasa de las soluciones a la propia validez de las conclusiones científicas. Es muy diciente que en el caso de la democratización ecológica en la gestión del agua en Nueva Zelanda, Memon et al. (2011), concluyeran justamente que la ciencia, además de tener dificultades para pronosticar, cambiaba los términos del debate (desde la calidad a la cantidad del agua).

Es notorio que en el ejemplo de la PPC el papel de los científicos haya mudado paralelamente a la reforma de 2013. Tras examinar el funcionamiento de MariFish, Holmes y Lock (2010) sugieren, que la manera de vehicular el conocimiento científico en el caso de las políticas pesqueras ha influenciado el resultado del diseño de las mismas. Evidentemente si este es el caso, podemos desde ya emitir la hipótesis según la cual esto se debe al efecto de encuadre. Sin embargo es aún más significativo que la participación del proceso que se dio entre 2009 y 2013 llevara a más diálogo, permitiendo que los científicos no monopolizaran la estructuración del diagnóstico. Se habría dado pues una modificación de los CT ex ante. También se habrían dado modificaciones ex post como lo sugiere la delegación científica de la reforma de 2013.

El análisis de Carter (2013) sobre la PPC nos corrobora esta intuición. Carter parte de un enfoque claramente crítico y se felicita de que los actores de la sociedad civil (eONGs, organizaciones pesqueras, organizaciones de consumidores) hayan puesto en duda las conclusiones científicas. La relación que se da en la PPC entre la esfera política y la científica es a parecer de este autor, paradigmática: "The case of EU fisheries is extremely relevant to this debate, not least because of its history of policy failure to manage fish stocks sustainably and the degree of uncertainty over whether this is changing.” (2013, p.28) Entonces, según Caitríon A. Carter, en la PPC se habría dado una politización del consejo científico, induciendo una preferencia por herramientas clásicas de acción: "From 1983, and the setting up of the EU's Common Fisheries Policy (CFP), until its second reform in 2002, dominant ways for assessing impacts were given content by the 'command and control' tradition." (2013, p. 29)

\footnotetext{
${ }^{4}$ A saber: 1) tecnocracia; 2) mandatos extensos; 3) mandatos limitados; 4) 'servidores del poder'.
} 
Finalizando, el paso de la PPC hacia la gestión de ecosistemas se habría dado precisamente por la apertura del monopolio de los científicos. Hasta entonces centrados en especies, estos habían dejado de lado el análisis más holístico en el cual toda cuota aplicada a una especie tiene el potencial de desregular otras. Empero la posición conservadora y simplista de la ciencia en la PPC se habría dado por una insuficiencia de recursos para la investigación. En definitiva, en el caso de la PPC estaríamos ante un PCh que precisamente está ligado a la introducción de esa apertura y una discusión a largo plazo (Carter, 2013, p. 32). Como lo hemos sugerido en las otras tesis, también estaríamos ante una modificación en la repartición de los costes de transacción ligados a la modificación institucional, que si bien no es democratización ecológica, retoma algunos conceptos de esta.

\section{Tesis 9: Mucho o poco, pero bien repartido}

Todos los autores que han usado los CT para el análisis de las PPM han reproducido la conclusión dominante de los economistas según la cual los actores buscan reducir los CT e incluso establecen estrategias para ello. Probablemente esta sea la mayor limitación que le podemos encontrar al uso de los TC y con razón. Partiendo de los conceptos centrales de la ciencia política, resulta obvio que los costes de transacción no solo son costes sino también relaciones de poder. La búsqueda de información, la creación de entes investigativos, la institucionalización de órganos consultivos, el establecimiento de agencias reguladoras e implementadoras: todas las acciones relacionadas con los CT pueden suponer relaciones de poder.

La heurística según la cual los altos CT son malos es una peligrosa simplificación. Dejan de lado la lectura según la cual los altos CT pueden ser beneficiosos porque permiten establecer unas relaciones entre actores donde se crean relaciones de dependencia. Estas relaciones podrían entonces llevar a mayor acercamiento y por ende PCh. Es decir, los presupuestos de Laura McCann (2013), Anthea Coggan et al. (2010) o Graham. R. Marshall (2013) por solo citar los principales, no pueden ser extendidos a la ciencia política. Este punto modifica, como bien se puede suponer, una conclusión esencial en relación al policy change. La existencia de PCh en contextos de altos costes de transacción (como en el caso de la PPC) mostraría de facto ese error de la simplificación de los economistas. Inclusive, es precisamente porque los CT responden a relaciones de poder que permiten analizar el PCh. Si el presupuesto de los autores dominantes fuera cierto, entonces no deberían de existir decisiones eficientes en contextos de altos CT.

En definitiva, la perpetuación del presupuesto económico de la necesidad de bajos CT se debe, a nuestro humilde parecer, al hecho según el cual se ha dejado de lado la explicación relacionada con la repartición de los CT. No se puede pues entender las variaciones en montos sin relacionarlo con la repartición de los mismos entre todos los actores, tanto públicos como privados. 


\section{Tesis 10: La relevancia de los sesgos cognitivos y las heurísticas}

Para finalizar nuestras diez tesis no podemos dejar de lado la relevancia de los sesgos que todo decisor tiene. Chet A. Bowers (1992) insiste en que nuestro sistema de valores y nuestras prácticas culturales son deficitarios en relación al medioambiente, tanto desde el punto de vista de la educación conservadora como liberal. Ambos pondrían al ser humano en una perspectiva lineal que reproduciría las estructuras sociales anteriores. Para Bowers, la educación liberal tiende a centrarse en el individualismo y el racionalismo, lo cual deja de lado la naturaleza como hecho relevante del humanismo. Según este mismo autor, nuestro sistema educativo tendería a incentivar un éxito personal que incluye la contextualización frente al grupo pero deja fuera de ese contexto la naturaleza. Por todo ello tendríamos un punto de encuentro entre la crítica conservadora y ecológica sobre el fracaso escolar para formar ciudadanos adaptados al mundo de hoy (Bowers, 1992, p. 40).

Ese fiasco no es de fácil solución y reside en la perpetuación de cosmovisiones frente a la cual una tentativa de cambio sobre la base de la racionalización sería inútil debido a la necesaria complejidad derivada del multiculturalismo (Bowers, 1992, p. 31). Sobre la base de la reflexión de Bowers podríamos sacar algunas conclusiones sobre los términos de la agenda de problemas medioambientales: 1) Reproducimos las matrices de análisis que hemos aprendido. 2) No podemos deshacernos de nuestros valores con solo quererlo. Para cambiarlos a nivel educativo debemos partir desde valores naturalmente presentes en otras sociedades y no desde una confianza excesiva en la racionalidad. 3) El modo de creación de los problemas en la agenda pública reproduce los errores que deberíamos tratar de corregir.

Dicho esto, podemos sugerir que el ser humano es en relación a la crisis ecológica, su propio límite. Tiene dificultades para apreciar el peligro en razón de su rígida percepción de la finitud además de perpetuar la trampa heurística de que más es igual a mejor. Los recientes desarrollos de la economía sobre la base de la psicología han aportado claves de respuesta sobre los costos hundidos al igual que sesgos como el escalamiento en el compromiso. Todos estos, si bien son de difícil evaluación, tienen una directa influencia sobre los costes de transacción.

En el caso concreto de la paradoja del aumento de compromiso en términos de Staw (1976) aplicado a la PPC, vemos que el incrementalismo lindblomiano sí que estaría ligado a la falta de voluntad o incapacidad para modificar el diseño elegido para una política. Es decir, la ausencia de PCh se debería también a un sesgo cognitivo en el cual nos cuesta reconocer el fracaso. La evolución del PPC se ajusta perfectamente a esta descripción y sospechamos, como no, que la perpetuación de una apuesta inicial infructuosa también resulta más fácil puesto que, como lo sugiere Staw, el aumento del compromiso también se acompaña por un aumento del gasto. Poniéndolo en paralelo con los CT no es pues de extrañar que se llegara a unos costos hundidos tan altos que facilitaran esa reforma del 2013. 


\section{Conclusiones}

Hemos visto a lo largo de toda esta reflexión algunas intuiciones sobre el papel de los costes de transacción como limitantes e incentivos para el cambio en las políticas públicas. El acercamiento clásico desde la ciencia política y desde los costes de transacción en economía dejan de lado algunas especificidades de los procesos de toma de decisión que hemos querido tener en cuenta. Hemos igualmente evaluado los tres principales enfoques (desarrollo sostenible, modernización y democratización ecológicas) desde el punto de vista de los costes de transacción y hemos puesto en paralelo las hipótesis con el caso de la política pesquera común. Nuestras hipótesis apuntan a que los CT sirven de transmisores y reguladores de las relaciones de poder y que como tales, pueden facilitar la comprensión de los limitantes a los cambios en las políticas públicas.

Nuestra reflexión es limitada, mas sería de especial interés que sobre la base de estas intuiciones se llevara a cabo una revisión de los presupuestos básicos en la aplicación de los costes de transacción al análisis de las políticas así como una crítica constructiva de la mono-direccionalidad de las teorías politológicas sobre el policy change. A fin de cuentas, se es demasiado confiado si se piensa que la ciencia política podrá proponer soluciones para engendrar mayores cambios en las políticas sin antes explicar su escasez. Los obstáculos a una mayor acción política a favor de la preservación ambiental no deberían solo ser vistos como un mero debate ecológico o inclusive ecologista. En efecto, de lo que se trata aquí es, ni más ni menos, que de los límites de la democracia.

\section{Referencias}

Aitken, M. (2012). Changing climate, changing democracy: a cautionary tale. Environmental Politics, 21(2), 211-229. doi:10.1080/09644016.2012.651899

Attfield, R. (1998). Environmental Ethics and Intergenerational Equity. Inquiry, 41(2), 207-222. doi:10.1080/002017498321878

Avinash, K. D. (1996). The making of economic policy: a transaction-cost politics perspective. Cambridge: MIT Press.

Berger, G., Flynn, A., Hines, F., y Johns, R. (2001). Ecological Modernization as a Basis for Environmental Policy: Current Environmental Discourse and Policy and the Implications on Environmental Supply Chain Management. Innovation, 14(1), 55-72. doi:10.1080/13511610125074

Birner, R., y Wittmer, H. (2009). Making Environmental Administration more Effective: A Contribution from New Institutional Economics. En V. Beckmann y M. Padmanabhan (Eds.). Institutions and Sustainability. (pp. 153-173). Dordrecht: Springer Netherlands. doi:10.1007/978-1-4020-9690-7 
Blowers, A. (1997). Environmental Policy: Ecological Modernisation or the Risk Society? Urban Studies, 34(5-6), 845-871.

Boulton, J. (2010). Complexity and Philosophy. Complexity Theory and Implications for Policy Development. E:Co, 12(2), 31-40.

Bourg, D. y Whiteside, K. (2010). Vers une démocratie écologique. Paris: Coédition Seuil-La République des idées.

Boutilier, R. (2005). New Horizons in Research on Sustainable Organisations. Chapter 1. En Views of sustainable development (pp. 19-37). UK: Greenleaf Publishing.

Bowers, C. A. (1992). Education, Cultural Myths, and the Ecological Crisis: Toward Deep Changes. Suny Series. New York: State University of New York Press.

Boykoff, M. T., y Roberts, J. T. (2008). Human Development Report 2007 / 2008. Media Coverage of Climate Change : Current Trends, Strengths, Weaknesses. Media coverage of climate change : current trends, strengths, weaknesses. Disponible en: http://hdr.undp.org/sites/default/files/boykoff_maxwell_and_ roberts_j._timmons.pdf

Brand, U. (2010, junio). Sustainable Development and Ecological modernization- the Limits to a Hegemonic Policy Knowledge. Innovation: The European Journal of Social Science Research, 23(2), 135-152. doi:10.1080/13511610.2010.522403

Brint, S. (1990). Rethinking the policy influence of experts: From general characterizations to analysis of variation. Sociological Forum, 5(3), 361-385. Disponible en: http://link.springer.com/article/10.1007/BFo1115092

Caballero Míguez, G. (2007). Nuevo institucionalismo en ciencia política, institucionalismo de elección racional y análisis político de costes de transacción: una primera aproximación. Revista de Investigaciones Políticas y Sociológicas, 6, 9-27. Disponible en: http://dspace.usc.es/handle/10347/8319

Caddy, J. F., y Seijo, J. C. (2005). This is more difficult than we thought! The responsibility of scientists, managers and stakeholders to mitigate the unsustainability of marine fisheries. Philosophical Transactions of the Royal Society of London. Series B, Biological Sciences, 36o(1453), 59-75. doi:10.1098/rstb.2004.1567

Carter, C. A. (2013). Constructing sustainability in EU fisheries: Re-drawing the boundary between science and politics? Environmental Science \& Policy, 30, 26-35. doi:10.1016/j.envsci.2012.11.015

Clini, C., Musu, I., y Gullino, M. (2008). Sustainable development and environmental management: experiences and case studies (pp. 3-15). Springer New York. Dsponible en: http://link.springer.com/chapter/10.1007/978-1-4020-6598-9_1 
Coggan, A., Whitten, S. M., y Bennett, J. (2010). Influences of transaction costs in environmental policy. Ecological Economics, 69 (9), 1777-1784. doi:10.1016/j. ecolecon.2010.04.015

Cohen, M. J. (2006). Ecological modernization and its discontents: The American environmental movement's resistance to an innovation-driven future. Futures, 38(5), 528-547. doi:10.1016/j.futures.2005.09.002

Conceição-Heldt, E. (2006). Taking Actors' Preferences and the Institutional Setting Seriously: the EU Common Fisheries Policy. Journal of Public Policy, 26(3), 279-299. Disponible en: http://journals.cambridge.org/production/action/cj oGetFulltext?fulltextid=530152

Conceição-Heldt, E. (2008). Assessing the Impact of Issue Linkage in the Common Fisheries Policy. International Negotiation, 13 (2), 285-300. doi:10.1163/157180608 X320243

Connelly, J. y Smith, G. (Eds.) (2003). Politics and the environment: from theory to practice. London: Routledge.

Cruz, C. N. (2011). Convergencias y disparidades en las teorías sobre el cambio de las políticas públicas : una revisión preliminar y una propuesta de integración tipológica. Administración y Desarrollo, 39(54), 97-116.

Culiberg, B., y Bajde, D. (2013, septiembre). Consumer recycling: An ethical decision making process. Journal of Consumer Behaviour, doi:10.1002/cb

Deutz, P. (2009). Producer responsibility in a sustainable development context: ecological modernisation or industrial ecology? Geographical Journal, 175(4), 274-285. doi:10.1111/j.1475-4959.2009.00330.x

Dobson, A. (2007). Green Political Thought. London: Taylor \& Francis.

Dylan, A. (2012). Rethinking Sustainability on Planet Earth: A Time for New Framings. Electronic Green Journal, 1(34). Disponible en: http://search.ebscohost.com/ login.aspx?direct=true\&profile $=$ ehost\&scope $=$ site\&authtype $=$ crawler\&jrnl=1076 7975\&AN=87645212\&h=KTfpErZcnGNIbuiOcxxnfjnDCoseFhLv1y\%2F4pKvoTZ JdOAeImOmq2fKKXSvMxVqGd7lFSBJXDnUDqQ3VPbe\%2F1Q\%3D\%3D\&crl=c

Ecological Modernisation as a framework for sustainable fresh water governance (2010). Land Use Policy, 28 (3), 534-541. doi:10.1016/j.landusepol.2010.10.006

Elgie, R., y McMenamin, I. (2005). Credible Commitment, Political Uncertainty or Policy Complexity? Explaining Variations in the Independence of Non-majoritarian 
Institutions in France. British Journal of Political Science, 35(3), 531-548. doi:10.1017/Sooo7123405000281

Fine, J. D., y Owen, D. (2005). Technocracy and Democracy : Conflicts between Models and Participation in Environmental Law and Planning. Hastings Law Journal, 56(24), 901-982.

Gutmann, A. y Thompson, D. (1996). Democracy and disagreement. Boston: Belknap Press, Harvard University Press.

Hadjimichael, M., Edwards-Jones, G., y Kaiser, M. J. (2010). Distribution of the burden of fisheries regulations in Europe: The north/south divide. Marine Policy, 34(4), 795-802. doi:10.1016/j.marpol.2010.01.021

Hatchard, J. L., y Gray, T. S. (2014). From RACs to Advisory Councils: Lessons from North Sea discourse for the 2014 reform of the European Common Fisheries Policy. Marine Policy, 47, 87-93. doi:10.1016/j.marpol.2014.02.015

Hilborn, R. (2012, julio). The evolution of quantitative marine fisheries management 1985-2010. Natural Resource Modeling, 122-145. Disponible en: http://onlinelibrary.wiley.com/doi/10.1111/j.1939-7445.2011.00100.x/full

Holmes, J., y Lock, J. (2010). Generating the evidence for marine fisheries policy and management. Marine Policy, 34(1), 29-35. doi:10.1016/j.marpol.2009.04.004

Howlett, M., y Rayner, J. (2006). Understanding the historical turn in the policy sciences: A critique of stochastic, narrative, path dependency and process-sequencing models of policy-making over time. Policy Sciences, 39(1), 1-18. doi:10.1007/ s11077-005-9004-1

Irvine, J. R. (2009). The successful completion of scientific public policy: lessons learned while developing Canada's Wild Salmon Policy. Environmental Science \& Policy, 12 (2), 140-148. doi:10.1016/j.envsci.2008.09.007

Jayal, N. G. (2001). Balancing Political and Ecological Values. Environmental Politics, 10 (1), 65-88. doi:10.1080/714000508

Jeffery, M. (2005). Environmental Ethics and Sustainable Development: Ethical and Human Rights Issues in Implementing Indigenous Rights. Macquarie J. Int'l \& Comp. Envtl. L., 2, 4-5. Disponible en: http://heinonlinebackup.com/hol-cgibin/get_pdf.cgi?handle=hein.journals/macqjice2\&section $=7$

Jones, B. D. y Baumgartner, F. R. (2005). The politics of attention: how government prioritizes problems. Chicago: University Of Chicago Press. 
Krutilla, K. (2010). Transaction Costs and Environmental Policy: An Assessment Framework and Literature Review. International Review of Environmental and Resource Economics, 4(3-4), 261-354. doi:10.1561/101.00000035

Lindblom, C. E. (1991). Zapico Goñi (Trad.). El proceso de elaboración de las políticas públicas. Madrid: Ministerio para las Administraciones Públicas.

Marshall, G. R. (2013). Transaction costs, collective action and adaptation in managing complex social-ecological systems. Ecological Economics, 88, 185-194. doi:10.1016/j.ecolecon.2012.12.030

McCann, L. (2013). Transaction costs and environmental policy design. Ecological Economics, 88, 253-262. doi:10.1016/j.ecolecon.2012.12.012

McCann, L., y Easter, K. (1999). Transaction costs of policies to reduce agricultural phosphorous pollution in the Minnesota River. Land Economics, 75(3), 402-414. Disponible en: http://www.jstor.org/stable/10.2307/3147186

McCann, L., y Easter, K. W. (2004). A framework for estimating the transaction costs of alternative mechanisms for water exchange and allocation. Water Resources Research, 40 (9).doi:10.1029/2003WRoo2830

McKinney, M., y Kemmis, D. (2011). Collaboration and the Ecology of Democracy. Human Dimensions of Wildlife, 16(4), 273-285. doi:10.1080/10871209.2011.585435

McShane, K. (2009). Environmental Ethics: An Overview. Philosophy Compass, 4(3), 407-420. doi:10.1111/j.1747-9991.2009.00206.x

Memon, P. A., Kirk, N. A., y Selsky, J. W. (2011). Limits to Ecological Modernisation as a framework for sustainable fresh water governance. Land use policy, 28(3), 534-541.

Mol, A. P. J. (1999). Ecological modernization and the environmental transition of Europe: between national variations and common denominators. Journal of Environmental Policy \& Planning, 1(2), 167-181. doi:10.1080/714038532

Mol, A. P. (2000). The environmental movement in an era of ecological modernisation. Geoforum, 31(1), 45-56. doi:10.1016/Soo16-7185(99)ooo43-3

Murphy, J., y Gouldson, A. (2000). Environmental policy and industrial innovation: integrating environment and economy through ecological modernisation. Geoforum, 31(1), 33-44. doi:10.1016/Soo16-7185(99)00042-1

Pannell, D. J., Roberts, A. M., Park, G., y Alexander, J. (2013). Improving environmental decisions: A transaction-costs story. Ecological Economics, 88, 244-252. doi:10.1016/j.ecolecon.2012.11.025 
Parsons, W. (2007). Políticas públicas. Una introducción a la teoría y práctica del análisis de políticas públicas. Buenos Aires: Miño y Dávila.

Pastoors, M. A. (2014, diciembre). Exponential growth in the number of words used for the European Common Fisheries Policy (CFP): Does better management require more text? Marine Policy, 46, 101-104. doi:10.1016/j.marpol.2014.01.008

Sabatier, P. A. (Ed.) (1999). Theories of the Policy Process. Boulder: Westview Press.

Sabatier, P. A. y Jenkins-Smith, H. C. (1993). Policy change and learning: an advocacy coalition approach. Boulder: Westview Prees.

Salomon, M., y Holm-Müller, K. (2013). Towards a sustainable fisheries policy in Europe. Fish and Fisheries, 14(4), 625-638. doi:10.1111/faf.12009

Sarigiannis, D. A, y Hansen, U. (2012). Considering the cumulative risk of mixtures of chemicals - a challenge for policy makers. Environmental Health : A Global Access. Science Source, 11 Suppl 1, S18. doi:10.1186/1476-069X-11-S1-S18

Scholz, R. W., Ulrich, A. E., Eilittä, M., y Roy, A. (2013). Sustainable use of phosphorus: a finite resource. The Science of the Total Environment, 461-462, 799-803. doi:10.1016/j.scitotenv.2013.05.043

Stone, D. (2001). Policy paradox: The art of political decision making. New York: W. W. Norton \& Company.

Staw, B. (1976). Knee-deep in the big muddy: A study of escalating commitment to a chosen course of action. Organizational Behavior and Human Performance, 44, 27-44. Disponible en: http://www.sciencedirect.com/science/article/ pii/0030507376900052

Surís-Regueiro, J. C., Varela-Lafuente, M. M., y Garza-Gil, M. D. (2011). Evolution and perspectives of the Fisheries Structural Policy in the European Union. Ocean \& Coastal Management, 54 (8), 593-600. doi:10.1016/j.ocecoaman.2011.05.008

Tversky, A., y Kahneman, D. (1981). The framing of decisions and the psychology of choice. Science, 211(4481), 453-458. Disponible en: http://www.sciencemag. org/content/211/4481/453.short

Ungaro, D. (2005). Ecological Democracy. International Review of Sociology, 15 (2), 293-303. doi:10.1080/03906700500159631

Warner, R. (2010). Ecological modernisation theory: towards a critical ecopolitics of change? Environmental Politics, 19(4), 538-556. doi:10.1080/09644016.2010.489710 